O corpo humano morto: utilização do cadáver para a pesquisa científica e para a doação de órgãos

The dead human body: corpse utilization for scientific research and donation of organs

\author{
João Beccon de Almeida Neto \\ Faculdade de Direito, Laboratório de Bioética e Ética Aplicada a Animais da \\ Pontifícia Universidade Católica do Rio Grande do Sul (PUCRS), Porto Ale- \\ gre, Rio Grande do Sul, Brasil. \\ beccon@via-rs.net
}

Marilise Kostelnaki Baú

Faculdade de Direito, Laboratório de Bioética e Ética Aplicada a Animais da Pontifícia Universidade Católica do Rio Grande do Sul (PUCRS), Porto Alegre, Rio Grande do Sul, Brasil.

mkbau@rigel.com.br

Jussara de Azambuja Loch

Faculdade de Medicina, Laboratório de Bioética e Ética Aplicada a Animais da Pontifícia Universidade Católica do Rio Grande do Sul (PUCRS), Porto Alegre, Rio Grande do Sul, Brasil.

juloc@terra.com.br

\title{
Gabriel Vieira Bilhalva
}

Faculdade de Direito.Laboratório de Bioética e Ética Aplicada a Animais da Pontifícia Universidade Católica do Rio Grande do Sul (PUCRS), Porto Alegre, Rio Grande do Sul, Brasil.

gabrielbilhalva@hotmail.com

\section{Anamaria Gonçalves dos Santos Feijó}

Faculdade de Biociências. Laboratório de Bioética e Ética Aplicada a Animais da Pontifícia Universidade Católica do Rio Grande do Sul (PUCRS), Porto Alegre, Rio Grande do Sul, Brasil.

agsfeijo@pucrs.br

Resumo: Este artigo visa fazer uma reflexão sobre as legislações referentes à doação de órgãos, bem como sobre a doação de corpos, procurando demonstrar a orientação e o desenvolvimento do tema no Direito pátrio. Sob o foco da bioética, se ressaltará o choque axiológico das normas jurídicas brasileiras. Apesar de que, moral e juridicamente, tenham idêntico valor, o corpo humano como fonte de conhecimento científico é tratado de forma diferente daquele, 
cuja finalidade é a doação de órgãos. Enquanto os princípios da doação de órgãos são protegidos pela condição sine qua non de autorização expressa seja do doador, enquanto vivo, seja de familiar ou responsável, quando morto - no caso da doação de corpos, nenhum destes princípios é observado: usa-se o corpo num sentido utilitarista, sendo esta prática nitidamente contraditória em relação à primeira. Defendendo uma manifestação autêntica de uma sociedade democrática, os autores sugerem um diálogo social amplo sobre o uso de cadáveres para a pesquisa, bem como propõem a adequação das políticas públicas no sentido de respeitar a vontade expressa do indivíduo para uso de seu corpo pos mortem, priorizando como fonte de doação de corpos a autonomia da vontade do doador e não os corpos não reclamados.

Palavras-chave: Bioética. Direitos da personalidade. Cadáver. Doação de órgãos. Doação de corpos.

\begin{abstract}
This article aims to reflect on the legislation relating to organ donation and body donation, and seeks to demonstrate the guidelines and development of this matter within Brazilian law. From the perspective of bioethics, the axiological clash of the Brazilian legal rules is emphasized. Even though the human body has the same moral and legal values, its use as a source of scientific knowledge is treated differently from its use for organ donation. Whereas the principles of organ donation are protected by the sine qua non condition of express authorization, either by the donor, while still alive, or by family members or the individual legally responsible, after death, in the case of body donation neither of these principles is observed. The corpse is used in a utilitarian manner, a practice that is clearly contradictory to the first principle. Advocating an authentic manifestation of a democratic society, the authors suggest a wide-ranging social dialogue on the use of cadavers for research. They also propose that public policies should be adapted such that the individual's express wish regarding the use of his body after death is respected, with priority given to the autonomy of the donor's wishes as the source of body donation, rather than to the use of unclaimed bodies.
\end{abstract}

Key words: Bioethics. Personality rights. Cadaver. Organ donation. Body donation. 


\section{Revista Brasileira de Bioética}

A valorização do cadáver no decorrer da história esteve sempre vinculada à memória de quem ele foi antes de morrer, confundindo-se o corpo com a pessoa. Coulanges, a partir de seu estudo, mostra a proteção que os familiares davam ao cadáver já no período Antigo ${ }^{1}$ : acreditavam que a alma da pessoa morta permanecia ligada à família (1). O parente morto constituía-se em um deus protetor da propriedade $^{2}$ cabendo aos familiares, até a sexta geração, prestar oferendas ao mesmo. Adorado apenas pela família, só a ela protegia. Cada família tinha os seus protetores do lar que, na realidade, eram os seus antepassados (1).

Carnelutti, de forma diferente, define que o "homem é, efetivamente, continente e conteúdo, corpo e espírito. Pessoa é apenas espírito. Corretamente, a pessoa não é o homem, mas está no homem" (2). A personalidade existe enquanto existir o espírito ou, pelo menos, o interesse deste em ser tutelado. A memória está diretamente relacionada com esta essência abstrata presente no corpo.

O indivíduo morto, ainda nos dias atuais, tem sua memória salvaguardada por parentes e tutelada pelo direito de personalidade a nível jurídico. Se o indivíduo não tem esta memória, deixa de existir e passa a ser apenas um cadáver, algo que já foi alguém, ausência da pessoa, mas apenas algo! Como dar valor a algo que não tem valor? O que acontece com os cadáveres não reclamados, sem família? Como valorar o corpo sem memória? Podem estes corpos ser coisificados em função dessa situação?

Implicações morais, culturais e jurídicas envolvem a utilização do corpo humano morto, total ou em partes. Entendemos que os conflitos morais, advindos do uso do cadáver não reclamado, também podem ser discutidos de forma multidisciplinar merecendo espaço no âmbito da bioética, já que essa situação desafia valores éticos muitas vezes não refletidos, mas assumidos por um determinado grupo social.

A bioética, entendida por Gracia (3) como o novo semblante da ética científica, preconiza aceitar o princípio da autonomia como uma

1 Período ligado à origem de Grécia e Roma.

2 Os parentes mortos eram enterrados nos limites da propriedade, junto ao deus Termo. "O domicílio mostra-se inviolável. Segundo a tradição romana, o deus doméstico repelia o ladrão e afastava o inimigo". Coulanges. Op.cit. p. 88. 
forma eticamente correta de respeito às pessoas e suas escolhas. $\mathrm{Na}$ maioria das sociedades contemporâneas, este é o princípio respeitado e salientado como fundamento para a doação de órgãos. Outro ponto interessante é a questão ética do doador morto. Nenhuma sociedade aceita retirar órgãos de pessoas vivas (exceto os que são duplos). Porém, na situação do cadáver não reclamado, como identificar esse respeito à vontade do morto? Pode-se utilizá-los como ferramenta didática em nome do interesse maior da sociedade em uma formação profissional específica? Não estaríamos impondo como presumida a vontade do doador, que na verdade não se manifestou, na tentativa de suprir a falta de corpos, pois sabemos que em nossa cultura, apenas um número ínfimo de corpos é doado espontaneamente para estudo?

Nossa proposta de reflexão, fundamentada em preceitos morais e legais, insere-se exatamente neste contexto, quando o cadáver não reclamado é usado sem que haja uma política de restrição para aquelas situações em que a utilização de corpos para o ensino e pesquisa é realmente necessária.

\section{Princípio da autonomia}

Na história da filosofia o conceito de autonomia, termo derivado do grego (auto, próprio e nomos, lei), aparece freqüentemente associado à idéia de liberdade. Estabelece a possibilidade do exercício da autonomia; a capacidade do indivíduo tomar decisões que venham afetar sua vida, sendo própria, então, apenas ao homem livre.

O conceito moderno de autonomia surge com a escola filosófica de Kant. Para ele o homem age por dever de acordo com sua lei moral interna. A capacidade do ser humano em optar pelas normas e valores que entende como válidos, sem intervenção heterônoma, é entendida como autonomia.

Em Crítica da razão pura (4), Kant discorre sobre a liberdade de ação, defendendo que a razão é a consciência do indivíduo sobre suas leis morais só admitidas com a liberdade. Porém, é em outra obra, Crítica da razão prática (5), que esse autor enfatiza a autonomia como fundamento do Imperativo Categórico: "ela é o princípio unificante de todos os princípios práticos". Entende que a autonomia da vontade é que dará a sustentabilidade para o imperativo categórico, a ser se- 


\section{Revista Brasileira de Bioética}

guido se o indivíduo for livre para fazê-lo:

"a autonomia da vontade é o único princípio de todas as leis morais e dos deveres conformes a elas: contrariamente, toda heteronomia do arbítrio não só não funda obrigação alguma mas, antes, contraria o princípio da mesma e da moralidade da vontade"(6).

Para Kant, então, o homem só é livre porque pode respeitar a vontade que tem de agir segundo sua lei moral interna, sua razão. Já Stuart Mill (7), como representante do utilitarismo, entende a autonomia como ausência de coerção sobre a capacidade de pensamento e ação do indivíduo, como o direito que tem de expressar opinião divergente àquela defendida pela sociedade vigente. Guisán (8) salienta que, na concepção utilitarista de Mill, a sociedade deve garantir os meios para que o homem se realizasse como pessoa, alcançando a felicidade. Ao indivíduo seria dado o direito de divergir do Estado que não lhe oferece as condições necessárias a esta realização. Em outras palavras, a autonomia individual dar-se-ia pelo direito à opinião divergente. Em contrapartida, Mill entende a tolerância como virtude social imprescindível para garantir a liberdade para externar essa opinião (7).

Como se pode constatar, enquanto a ética deontológica de Kant coloca normas e valores como inquestionáveis, Mill defende que as normas morais terão valor se visarem o bem estar geral, podendo ser questionadas se não adequadas. Porém, ambos os autores entendem a autonomia dos sujeitos como um direito que deve ser respeitado. Para Kant, não respeitar a autonomia seria ir contra a essência íntima do ser humano, seria utilizá-lo como meio apenas e não como fim, seria impor-lhe uma norma externa tolhendo sua liberdade. Para este autor sobrepõe-se o conceito de liberdade com o de indivíduo autônomo já que, para ele, não pode haver ser humano autêntico sem liberdade, assim como sem autonomia. Para Mill a importância da autonomia reside no fato dos homens reivindicarem as condições necessárias para lograr a felicidade e alcançar a máxima utilitarista, sendo a ausência de coerção condição indispensável para isso.

Na bioética, o respeito à autonomia aparece, em 1979, como um dos quatro princípios básicos não absolutos (respeito à autonomia, beneficência, não-maleficência e justiça), que estabeleceram a linha de 
ação estadunidense conhecida como Principialismo, voltada à orientação de conflitos oriundos da área biomédica, proposta na obra de Beauchamp e Childress (9). É importante salientar que essa obra foi apresentada em contexto plural e antecedida por importantes documentos como o Relatório Belmont. Nessa proposta, o respeito à autonomia incorpora a autodeterminação da pessoa e sua capacidade de decidir o melhor para si. Esse princípio fundamenta-se na dignidade da pessoa humana, defendida tanto na ética deontológica de Kant, como na escola utilitarista de Mill (10).

Enquanto autonomia significa o autogoverno para tomar decisões que venham afetar sua vida, saúde e integridade, o respeito a essa autonomia, defendido no Principialismo, seria o reconhecimento de que ao indivíduo cabe a tomada de decisão segundo seu plano de vida, fundamentado em sua crença, aspirações e valores próprios, mesmo quando estes não coincidem com os dominantes na sociedade (11).

Constata-se, então, no cenário social, que a autonomia seria a maneira como o ser humano impõe-se como pessoa e cidadão por meio de suas convicções e escolhas no que tange à sua vida e corpo, não afetando negativamente outras pessoas, na sociedade em que está inserido. O respeito à autonomia refletiria, então, como a sociedade democrática propicia espaço para exercer essa liberdade de opção. Embora relativizado, o Direito também prevê o respeito à vontade do indivíduo nos Direitos de Personalidade, pelo menos em relação ao seu corpo ou parte dele.

\section{Aspectos jurídicos}

\section{Dos direitos de personalidade}

A Constituição, no artigo $5^{\circ}$, X, prevê a inviolabilidade da intimidade, da vida privada, da honra e da imagem da pessoa (12). Em seu artigo 199, parágrafo $4^{\circ}$, além de prever a existência de lei especifica sobre remoção de órgãos e partes do corpo, também proíbe qualquer tipo de comercialização de órgãos ou sangue.

O Código Civil (13) regula os direitos da personalidade na Parte Geral, Livro I, Capítulo II, do artigo 11 ao 21. São intransmissíveis, inalienáveis e irrenunciáveis os diretos da personalidade, salvo se lei específica não prever diferente (exceção, portanto), não podendo estes 


\section{Revista Brasileira de Bioética}

sofrer limitação voluntária (art. 11). Apesar da intransmissibilidade, a morte da pessoa promove, para fins de defesa judicial, a transmissibilidade do direito sobre a imagem (art. 12). A pessoa tem o direito de livre disposição gratuita do próprio corpo, tanto para transplantes (art. 13), como para fins altruísticos ou científicos (art. 14). O Código Civil também regula os direitos da pessoa ter nome e prenome, vida privada, bem como a proteção aos mesmos. Faz-se necessário destacar a proteção dada ao pseudônimo: tutela igual à dada ao nome (art. 19).

França (14) define os direitos da personalidade como sendo "as faculdades jurídicas cujo objeto são os diversos aspectos da própria pessoa do sujeito, bem assim as suas emanações e prolongamentos". Para Jabur (15) a "personalidade é apenas uma aptidão para exercer direitos e contrair obrigações". Nader (16), por sua vez, define como a expressão do Direito Natural, o princípio básico do direito à vida, e, portanto, de direitos subjetivos.

O primeiro diploma a prever os direitos da personalidade foi uma lei da Romênia, de 18 de março de 1895, que se limitava a prever o direito da pessoa ao nome. No mesmo sentido, temos a previsão legal do Código Civil alemão Bürgerliches Gesetzbuch (BGB), de 1900. Em 1907, o Código suíço consagrou o direito à designação personativa, isto é, o direito de cada pessoa a receber um nome que a identifique na vida em sociedade. No entanto, o grande avanço ocorreu justamente no Código Civil italiano, de 1942 (na época de Mussolini), no Livro I, Delle Personne e Della Famiglia. Este código não regula apenas o direito ao nome, mas envolve outros, como a tutela do direito ao nome, a tutela do pseudônimo, bem como à imagem e aos atos de disposição do próprio corpo, o que também se encontra no Código Civil brasileiro de 2002, similar ao italiano.

Foi praticamente a partir do século XX que os direitos de personalidade passaram a ser objetos de codificação. Acontecimentos importantes, como a Primeira Guerra Mundial e crises econômicas, propiciaram esta preocupação. A política econômica passou a ser questionada: a idéia de um Estado mínimo não tinha mais espaço no cenário internacional. Keynes propunha a política econômica da compensação, na qual o Estado tem um papel mais ativo na economia: de garantidor e de investidor (17). O Estado deveria garantir a estabilidade da economia para a promoção da iniciativa privada, e 
para tanto, investir em obras públicas de base. Mas Keynes defendia que estes investimentos deveriam ser momentâneos, o que não fora observado pelos estados, uma vez que estes viam nos mesmos uma mola propulsora angariadora de votos. Com isso, agora transformado em gestor, o papel do Estado não seria mais o de acumular capitais, e sim fomentar ações sociais. Sendo assim, temos o nascimento do chamado Estado de Bem-estar Social (Welfare State), no qual o comprometimento social é o carro-chefe. Mais do que natural, por conseguinte, é a idéia de uma maior proteção à dignidade da pessoa humana.

A partir da Segunda Guerra Mundial, assistiu-se o crescimento exponencial do capitalismo, o que levou a uma super valorização das forças econômicas. Tal processo contribuiu, inclusive, para a paulatina desconstrução do welfare state, ou para o surgimento do neoliberalismo, e, portanto, baseado na perspectiva econômica que eliminava as políticas sociais, deixando a regulação dessas necessidades ao mercado. Nesta nova perspectiva, a função do Estado não seria mais a de responsável direto pela execução das políticas sociais, mas sim, a de garantir a existência das mesmas à sociedade.

Tudo passa a ser observado pelo prisma social. Não é por menos que passa a ter a idéia de função social da propriedade, função social dos contratos e, porque não dizer também, função social da pessoa humana. O ser humano não existe como algo isolado; deve ser visto como membro de um grupo social, mas não como uma engrenagem ou peça, que forma a grande máquina sociedade: deve acrescentar; somar aos seus iguais. A autonomia privada é relativizada, o homem não é dono de si mesmo de forma absoluta. Seus interesses devem ser observados e respeitados, porém, até para o seu próprio bem, estes interesses devem estar em conformidade com os da sociedade. Se a autonomia do indivíduo fosse elevada ao grau máximo, estar-se-ia abrindo lacunas no ordenamento jurídico que poderiam tornar possível a reificação do ser humano, chegando ao ponto de relativizar o direito à vida. Isto é exatamente o contrário do que objetiva o Direito: desassistir a pessoa humana na sua dignidade:

"A vinculação dos direitos aos interesses superiores da coletividade e sua conciliação com as exigências sociais hão de cumprir-se 
mediante a extensão de garantias que assegurem ao indivíduo o pleno desenvolvimento de suas faculdades, porque afinal de contas é o homem, que nele está a raiz do mundo. Não é por acaso que os códigos modernos reafirmam e ampliam os direitos de personalidade"(18).

\section{O uso de cadáver não reclamado para ensino e pesquisa}

De acordo com o art. $2^{\circ}$ da Lei 8.501/92: o cadáver não reclamado junto às autoridades públicas, no prazo de 30 dias, poderá ser destinado às escolas de medicina, para fins de ensino e de pesquisa de caráter científico" (19). Poderá ter este destino, segundo o art. $3^{\circ}$ da mesma lei, tanto aquele sem identificação como aquele com identificação, mas que sobre o qual inexistem informações relativas a endereços de responsáveis legais ou parentes. Neste último caso, é dever da autoridade publicar notícias sobre o falecimento, a título de utilidade públi$\mathrm{Ca}$, nos principais jornais da cidade durante pelo menos dez dias.

Para que ainda possa haver reconhecimento, mesmo depois do encaminhamento do corpo, a autoridade ou instituição deverá manter os dados sobre o morto: relativos às características gerais, identificação, fotos do corpo, ficha datiloscópica, o resultado da necropsia, quando efetuada, e outros dados e documentos julgados pertinentes. É proibido encaminhar o corpo para fins de estudo quando houver indício de que a morte foi criminosa. Se a morte resultar de causa não natural, o corpo será, obrigatoriamente, submetido à necropsia no órgão competente.

Segundo a Lei, a utilização do cadáver para a pesquisa somente poderá ser feita por escolas de medicina e não estabelece o acesso a outros cursos que costumam utilizá-lo. Esta é uma crítica que se faz à lei, uma vez que outras áreas de formação igualmente necessitam de corpos para o estudo de anatomia ${ }^{3}$.

3 Atualmente existem diversos projetos de lei tramitando na Câmara dos Deputados com o objetivo de alterar o art. $2^{\circ}$ da Lei 8.501/92. O último é de autoria do então deputado federal Roberto Jefferson, datado do ano de 2004, sem movimentação desde junho de 2005 (Projeto de lei 4440/2004, disponível em: http://www2.camara.gov.br/ proposicoes, acessado em 16/01/2007). 


\section{A regulamentação da doação de órgãos}

Segundo Farias e Rosenvald (20), o direito à integridade física concerne à proteção jurídica do corpo humano, sua incolumidade física, incluída a tutela do corpo vivo e do corpo morto inteiro e em partes (tecidos, órgãos e partes do corpo suscetíveis de separação e individualização).

O corpo humano caracteriza-se por ser coisa extra commercium. A Magna Carta, juntamente com o art. $1^{\circ}$ da Lei $\mathrm{n}^{\circ}$. 9.434/97, veda qualquer tipo de comercialização de qualquer parte do corpo (21). Admite-se, a título de exceção, ato de disposição de partes do corpo humano vivo ou morto a título gratuito, com o objetivo científico ou altruístico, se não causar prejuízo ao titular, se vivo ou para depois da morte, conforme os artigos 13 e 14 do Código Civil.

Em regra, a pessoa maior e capaz pode, em vida, dispor gratuitamente de tecidos, órgãos e partes do corpo vivo, desde que sejam partes renováveis ou órgãos duplos. A revogação pode ser feita em qualquer tempo, pelo doador, antes da execução (21). A doação deve ter caráter de gratuidade, sendo necessária para a vida do receptor e a autorização deve ser feita preferencialmente por escrito e especificando claramente o material ou órgão que se deseja doar. Na doação para depois da morte veda-se que o doador escolha o beneficiário, por se tratar de ato altruístico, devendo ser respeitada a fila única de espera e, como salienta Ulhoa Coelho (22), o receptor poderá até mesmo se tratar de um desafeto do doador.

\section{Aspectos organizacionais e operacionais}

A universalização da saúde e a igualdade de oportunidades são garantidas pela Constituição Federal, nos artigos $3^{\circ}, 5^{\circ}$ caput e 196 :

"A saúde é direito de todos e dever do Estado, garantido mediante políticas sociais e econômicas que visem à redução do risco de doença e de outros agravos e ao acesso universal e igualitário às ações e serviços para sua promoção, proteção e recuperação" (12).

Em relação aos transplantes, e como forma de realizar o prescrito pela Constituição, foram criadas as Centrais de Notificação Capaci- 


\section{Revista Brasileira de Bioética}

tação e Distribuição de Órgãos (CNCDO), nos diferentes estados da federação, centralizando, organizando e promovendo uma mais eqüitativa distribuição de órgãos doados.

Comprovada a morte encefálica do doador, mediante declaração médica, pode-se de imediato providenciar a retirada dos órgãos doados, comunicando-se imediatamente a CNCDO do estado da federação em que o órgão foi retirado. Então, comunicado o óbito, a equipe de captação dirige-se ao nosocômio para realizar exames e informar à Central as características do doador. Esta promove o levantamento dos candidatos de acordo com a compatibilidade, com a finalidade de realizar, imediatamente, o transplante.

Já no caso do encaminhamento de cadáver não reclamado para as instituições de ensino, a formalidade do procedimento, especificamente em matéria não prevista na lei federal, regula-se pelo ordenamento de cada Estado da federação. De maneira geral cabe à instituição de ensino interessada, encaminhar à Direção do Departamento Médico Legal ofício solicitando a quantidade de corpos desejados. No caso específico do Rio Grande do Sul, as doações seguem a ordem de chegada dos respectivos pedidos, sendo cada instituição atendida com um cadáver por vez. As que necessitam mais de um cadáver, entrarão novamente na agenda de espera, tendo seu pedido mais uma vez atendido após todas as instituições solicitantes terem recebido. Os demais requisitos mínimos para o procedimento já foram ressaltados.

\section{Histórico jurídico}

Quando se analisa as origens e o desenvolvimento histórico-legislativo da doação de órgãos, verificar-se uma evolução: a primeira norma brasileira sobre o tema (Lei 4.280/63), estabelecia uma normatização restrita no que tange às "hipóteses de aproveitamento de órgão de cadáveres" (23). Em função disso, surge a Lei 5.479/68 (24), revogando aquela de 1963. Esta lei suavizou um pouco as restrições da lei anterior, pois permitia a retirada de órgãos de cadáver sem responsável - como o indigente, por exemplo. Depois desta lei, pode-se citar o que seria uma aproximação da maturidade no ordenamento: o Projeto de Lei 8.195/86, de autoria do então deputado federal Freitas Nobre. 
Visando simplificar o ato, esse Projeto de Lei tornaria a doação regra geral, excetuando apenas os casos de expressa determinação em sentido contrário. Na sua justificativa, Freitas Nobre defendia a prevalência do interesse da comunidade: "acima do interesse da família, o interesse social". O projeto foi arquivado pela mesa diretora da Câmara dos Deputados em agosto de 1986 (25). A lei sobre transplantes promulgada a seguir foi a Lei 8.489/92 (26), que prevaleceu até o advento da atual; cabe ressaltar que a mesma não trouxe maiores evoluções.

A atual lei de doação de órgãos, Lei 9.434/97, no seu texto original, previa que toda pessoa era doadora em regra, salvo manifestação expressa em contrário, registrada em carteira de identidade; porém, por pressão social, esse dispositivo foi revogado em 2001. Não entrando no mérito desta revogação, o fato é que hoje a doação de órgãos no Brasil não logrou progresso. Podemos inferir que esta lei não dá ênfase à autonomia do doador, uma vez que cabe aos familiares autorizar tais procedimentos:

"Art. $4 .^{\circ}$ A retirada de tecidos, órgãos e partes do corpo de pessoas falecidas para transplantes ou outra finalidade terapêutica, dependerá da autorização do cônjuge ou parente, maior de idade, obedecida a linha sucessória, reta ou colateral, até o segundo grau inclusive, firmada em documento subscrito por duas testemunhas presentes à verificação da morte" (21) .

Posicionando-se sobre essa alteração, Berlinguer e Garrafa afirmam que deixar na mão do Estado a decisão de doação de órgãos em lugar de outorgá-la aos parentes, salientaria o aspecto altruístico desta ação (27). Para esses autores, embora havendo o respeito pela dor dos parentes ou piedade pelo corpo morto, seria mais justo que fosse o próprio indivíduo, e não outros, a autorizar a retirada ou não de seus órgãos.

Existe ainda outro ponto importante que, apesar de sua previsão em normas anteriores, infelizmente retrocedeu. Trata-se da doação de 


\section{Revista Brasileira de Bioética}

órgãos de pessoas não identificadas ou, se identificadas, não reclamadas. Como levantado anteriormente, a Lei 5.479/68 considerou o tema, mas as leis posteriores não tiveram o mesmo cuidado. A lei de 1992 (19) foi omissa a ele, enquanto que a atual somente autoriza o uso de órgãos provenientes de cadáveres identificados cujos parentes expressem anuência a esta utilização.

\section{Conflito das normas}

No ordenamento jurídico brasileiro, o cadáver apresenta resquícios de personalidade; portanto, não é objeto. Adriano de Cupis clarifica a idéia:

"Se a personalidade não existe depois da morte, nem por isso deixa de ser considerado por parte do ordenamento jurídico. Pelo contrário, o corpo humano, depois da morte, torna-se uma coisa submetida à disciplina jurídica, coisa, no entanto, que, não podendo ser objeto de direitos privados patrimoniais, deve classificar-se entre coisas extra-commercium. Não sendo a pessoa, enquanto viva, objeto de direitos patrimoniais, não pode sê-lo também o cadáver, o qual, apesar da mudança de substância e função, conserva o cunho e o resíduo da pessoa viva. A comerciabilidade estaria, pois, em nítido contraste com tal essência do cadáver, e ofenderia a dignidade humana" (29).

Os resquícios de personalidade, entretanto, estão intimamente ligados à memória depositada neste corpo. No momento em que se configura a inexistência de memória, como é o caso do cadáver não reclamado, tem-se, portanto, simplesmente uma coisa ${ }^{5}$. A imemorialidade define-se como sendo a extinção total dos direitos da personalidade, por inexistir uma última vontade expressa ou por falta de herdeiros que queiram tutelar-lhe a memória.

5 Anteriormente trazemos a definição do cadáver como sendo res extra commercium. Não adentraremos nas definições do que é cadáver, em sua natureza jurídica, já que este não é o objetivo deste trabalho. Manteremos esta aceita pelo ordenamento jurídico brasileiro. 
A partir do exposto, é possível formular questionamentos importantes: por que se pode utilizar, sem expressa autorização, o corpo não reclamado para o ensino e pesquisa, mas não para remoção de tecidos, órgãos ou partes do mesmo para fins de transplante? Por que o tratamento diferenciado com relação à doação de órgãos em face da doação de corpos?

A Lei 8.501/92 legitima o aproveitamento de cadáveres não reclamados para fins de pesquisa. Esta lei de cunho utilitarista, isto é, que presume a doação em face do bem maior, que é o desenvolvimento do bem estar da sociedade, suprime de certa forma um suposto direito subjetivo (19). Entretanto, a análise da lei que normatiza a doação de órgãos permite detectar o oposto, pois privilegia o individual.

Não se pretende afirmar categoricamente que seja ideal uma lei servir de parâmetro para outra. O que se busca demonstrar é o conflito entre as normas, no que concerne a atos de mesma valoração, em uma mesma sociedade: doação de órgãos e doação de corpo.

O nosso sistema jurídico não contempla lei específica sobre a doação de corpos, nos moldes da doação de órgãos. Há somente o art. 14 do Código Civil (13). Sem entrar no mérito da questão, uma análise simples da Lei $\mathrm{n}^{\mathrm{o}}$. 8.501/92 permite perceber que sua formulação não objetivou grandes reflexões jus-filosóficas: foi feita almejando como fim maior disponibilizar cadáveres para o ensino e pesquisa.

A doação de corpos deveria ter sua importância elevada ao mesmo patamar da outorgada pela doação de órgãos, possuindo o mesmo respaldo jurídico. As leis nacionais demonstram preocupação em conscientizar a sociedade sobre a doação de órgãos. No entanto, não se detecta essa preocupação no que concerne à conscientização sobre a doação de corpos.

\section{Considerações finais}

No que tange ao Direito, o cadáver não apresenta valor em si mesmo, somente o indivíduo vivo o tem. Aquele não apresenta interesses como uma pessoa. A deliberação dos herdeiros nada tem com o direito de propriedade: eles representam a última vontade do indivíduo. Os resquícios de personalidade que o ordenamento jurídico prevê para o cadáver, estão justamente respaldados neste fundamento da memória 


\section{Revista Brasileira de Bioética}

da pessoa quando viva. Tanto é que a imemorialidade do corpo pos mortem o transforma em coisa sem valor (res nullius), uma vez que não existe última vontade e, sendo assim, não há porque falar em resquícios de personalidade.

Esta situação torna o corpo objeto de direito para fins de estudo e pesquisa. Aqui está a principal forma de obtenção de cadáveres pelas instituições: os cadáveres não reclamados. A segunda fonte provém da vontade do indivíduo. E esta é praticamente rara ou inexistente no Brasil. Então, o problema da falta de cadáveres para o estudo e pesquisa encontra-se no desprovimento de políticas governamentais, que fomentem a idéia da doação de corpos, no mesmo âmbito em que observamos nas campanhas de doação de órgãos. Acresce-se a isso o fato de não existir lei específica sobre o tema da doação de corpos. Este tema deveria ser tomado da mesma forma que o da doação de órgãos, mas seu tratamento está longe disto: ainda estamos intimamente ligados a misticismos e crenças cotidianas, senão, religiosas. Deve-se promover uma discussão moral e ética sobre a doação de corpos, fundamentada na autonomia do doador. Tal discussão precisa ser estabelecida, no intuito de conscientizar a sociedade e valorizar a importante função deste ato, para a melhoria da formação acadêmica dos futuros profissionais da área da saúde e da biociência.

Também é bastante discutida a falta de coerência constatada na sociedade no que concerne à doação de órgãos, no momento em que a autonomia do doador passa a depender da vontade dos parentes. Muitos acreditam que a legislação sofreu um retrocesso ao não mais aceitar a autorização presumida para os transplantes. A doação presumida, na qual a ausência de manifestação contrária à doação em documentos, indica a retirada dos órgãos sem a interferência familiar, foi adotada no Brasil, em 1997, pela promulgação da Lei 9.434 (21). A resistência da população a esse ordenamento compulsório explicitouse no grande número de documentos contendo o termo não-doador de órgãos. A sociedade brasileira não aceitou a doação presumida e a lei corroborou essa decisão em 2001, com a Lei 10.211 que extinguiu definitivamente a doação presumida, determinando que a retirada de órgãos de cadáver só ocorresse após a autorização familiar (28).

Entretanto pouco se fala dos cadáveres não reclamados usados para ensino e pesquisa. Para esses, que não têm parentes, vale a au- 
torização presumida, a mesma que foi negada pelo povo brasileiro quando da doação de órgãos. Detecta-se aqui uma incoerência! Um duplo padrão moral na regulação dos corpos de pessoas mortas.

Clotet (30) já afirmava, em 1993, que a sociedade precisa posicionar-se sobre certas mudanças. Dentre elas, salientava a necessidade de um padrão moral que pudesse ser compartilhado por pessoas de realidades diferentes. Acredita-se que um diálogo multidisciplinar sobre o uso de cadáveres para a pesquisa e a proposição de políticas públicas que respeitem a vontade expressa do indivíduo ao uso de seu corpo, seria uma maneira concreta de manifestação de uma sociedade democrática. Isso tornaria a proposição acima atual e relevante, priorizando como fonte de doação de corpos a autonomia da vontade do doador e não os corpos não reclamados.

Este trabalho é fruto do projeto Discussão Multidisciplinar sobre Aspectos Éticos e Legais em Relação à Utilização do Corpo Humano no Ensino e Pesquisa: do Transplante de Órgãos ao Cadáver, financiado pelo CNPq, no qual é orientadora Anamaria Gonçalves dos Santos Feijó, e bolsista João Beccon de Almeida Neto (PIBIC/CNPq).

\section{Referências}

1. Coulanges F. A cidade antiga: estudo sobre o culto, o direito, e instituições da Grécia e de Roma. Lisboa: Clássica Editora/A. M. Teixeira \& Cia.; 1950.

2. Carnelutti F. Teoria geral do direito. São Paulo: LEJUS; 1999.

3. Gracia D. Fundamentos de bioética. Madrid: Eudema Universidad; 1989.

4. Kant, I. Crítica da razão pura. Lisboa: Calouste Gulbenkian; 1994.

5. __ . Crítica da razão prática. Lisboa: Edições 70; 1986.

6. _ـ Fundamentação da metafísica dos costumes. São Paulo: Abril Cultural; 1980.

7. Mill JS. El utilitarismo: un sistema de la lógica. Madrid: Alianza Editorial; 1997.

8. Guisán E. Introducción. In: Mill JS. Op. cit.; 1997.

9. Beauchamp TL, Childress JF. Principles of biomedical ethics. $4^{\text {th }}$ edition. New York: Oxford University Press;1994.

10. Clotet J, Feijó AGS. Bioética: uma visão panorâmica. In: Clotet J, Feijó AGS, Oliveira MG. Bioética: uma visão panorâmica. Porto Alegre: EDIPUCRS; 2005. 11. Muñoz DR, Fortes PAC. O princípio da autonomia e o consentimento livre e esclarecido. In: Costa SIF, Garrafa V, Oselka G. (orgs.) Iniciação à bioética. Brasília: Conselho Federal de Medicina; 1998. 


\section{Revista Brasileira de Bioética}

12. Brasil. Constituição. Constituição da República Federativa do Brasil. Brasília, Senado Federal, 1988.

13. Brasil. Novo Código Civil Brasileiro. Curitiba/PR, Câmara Municipal de Curitiba, Diretoria de Informática, 10 de janeiro de 2002. Disponível em: http://www.cmc.pr.gov.br/down/ccivil.pdf. Acesso em: 16/10/2007.

14. França RL. Manual de Direito Civil. Vol 1. São Paulo: Revista dos Tribunais; 1971.

15. Jabur GH. Liberdade de pensamento e direito à vida privada: conflitos entre direitos da personalidade. São Paulo: Revista dos Tribunais; 2000.

16. Nader P. Curso de Direito Civil, Parte Geral. Vol 1. Rio de Janeiro: Forense; 2005.

17. Keynes JM. Teoria geral do emprego, do juro e do dinheiro. Rio de Janeiro: Fundo de Cultura; 1964.

18. Gomes O. A reforma do Código Civil, [S.I.] Bahia: Universidade Federal da Bahia (UFBA); 1965.

19. Brasil. Lei n. 8.501, de 30 de novembro de 1992. Dispõe sobre a utilização de cadáver não reclamado, para fins de estudos ou pesquisas científicas e dá outras providências. Diário Oficial da República Federativa do Brasil, Distrito Federal, 15 dez., 1992.

20. Farias CC, Rosenvald N. Direito Civil: teoria geral. Rio de Janeiro: Lumen Júris; 2006.

21. Brasil. Lei no 9.434, de 04 de Fevereiro de 1997. Dispõe sobre a remoção de órgãos, tecidos e partes do corpo humano para fins de transplante e tratamento e dá outras providências. Diário Oficial da República Federativa do Brasil, Distrito Federal, 5 fev., 1997.

22. Coelho FU. Curso de Direito Civil. Vol. I. São Paulo: Saraiva; 2003.

23. Brasil. Lei $\mathrm{n}^{\mathrm{o}}$ 4.280, de 06 de Novembro de 1963. Dispõe sobre a extirpação de órgão ou tecido de pessoa falecida. Diário Oficial da República Federativa do Brasil, Distrito Federal, 11 nov., 1963.

24. Brasil. Lei $\mathrm{n}^{\mathrm{o}}$ 5.479, de 10 de Agosto de 1968. Dispõe sobre a retirada e transplante de tecidos, órgãos e partes de cadáver para finalidade terapêutica e científica, e dá outras providências. Diário Oficial da República Federativa do Brasil, Distrito Federal, 14 ago., 1968.

25. Silva JAF. Tratado de direito funerário: teoria geral e instituições de direito funerário. São Paulo: Método; 2000.

26. Brasil. Lei $n^{\circ}$ 8.489, de 18 de novembro de 1992. Dispõe sobre a retirada e transplante de tecidos, órgãos e partes do corpo humano, com fins terapêuticos e científicos e dá outras providências. Diário Oficial da República Federativa do Brasil, DF, 20 nov., 1992.

27. Berlinguer G, Garrafa V. O mercado humano: estudo bioéticos da compra e venda de partes do corpo. $2^{\mathrm{a}}$. edição. Brasília: UnB; 2001.

28. Brasil. Lei $n^{\circ} 10.211$, de 23 de Março de 2001. Altera dispositivos da Lei $n^{\circ}$ 9.434, de 4 de fevereiro de 1997, que "dispõe sobre a remoção de órgãos, teci- 
dos e partes do corpo humano para fins de transplante e tratamento". Diário Oficial da República Federativa do Brasil, DF, 24. mar., 2001.

29. Cupis A. Os direitos da personalidade. Lisboa: Morais; 1961.

30. Clotet J. Por que bioética? Bioética. 1993; 1(1):13-9. 